\title{
Severe GI distress: Is clozapine to blame?
}

Amy Rasmussen, MD, Elizabeth Kistler, MD, Melanie Yabs, PharmD, BCPP, Ana Lupu, PharmD, Jessica Gannon, MD, Lori Arbutiski, RN, MSN, Rohit Das, MD, and K.N. Roy Chengappa, MD, MRCPsych

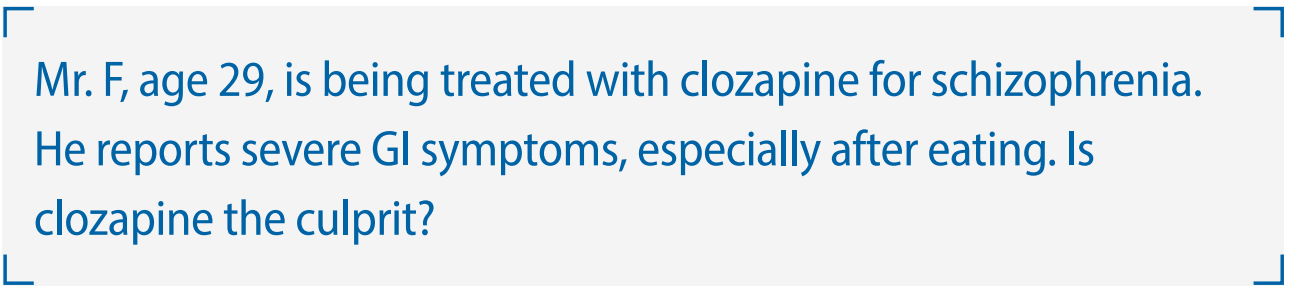

\section{CASE GI distress while taking clozapine}

Mr. F, age 29, has a history of psychiatric hospitalizations for psychotic episodes. It took a herculean effort to get him to agree to try clozapine, to which he has experienced a modest to good response. Unfortunately, recently he has been experiencing significant upper gastrointestinal (Gl) distress. He attributes this to clozapine, and asks if he can discontinue this medication.

\section{HISTORY Nausea becomes severe}

Mr. F, age 29, resides in a long-term residential setting for patients with serious mental illness who need additional support following acute hospitalization. He has treatmentrefractory schizophrenia. He first developed symptoms at age 18, and experienced multiple psychotic episodes requiring psychiatric hospitalizations that lasted for months. He has had numerous antipsychotic trials and a course of electroconvulsive therapy, with limited benefit.

More recently, Mr. F's symptoms began to stabilize on a medication regimen that includes clozapine, $350 \mathrm{mg} / \mathrm{d}$ at bedtime, and haloperidol, $2 \mathrm{mg} / \mathrm{d}$. He has not required psychiatric hospitalization for the past year.

Within months of initiating clozapine, Mr. F starts to complain daily about symptoms of worsening abdominal pain, abdominal bloating, nausea, intermittent episodes of emesis, and heartburn. The symptoms begin when he wakes up, are worse in the morning, and persist throughout the morning. He has experienced occasional mild constipation, but no diarrhea or weight loss. There have been no major changes in his diet, addition of new medications, or significant use of nonsteroidal anti-inflammatory drugs.

Mr. F's nausea worsens over the next several weeks, to the point he begins to significantly limit how much he eats to cope with it. His GI symptoms are also impacting his mood and daily functioning.

continued

Dr. Rasmussen is Child and Adolescent Psychiatry Fellow, Bradley Hospital, Alpert Medical School of Brown University, Providence, Rhode Island. Dr. Kistler is Associate Professor of Psychiatry, Western Psychiatric Hospital, University of Pittsburgh Medical Center, Pittsburgh, Pennsylvania. Dr. Yabs is Clinical Pharmacist, Psychiatry, Western Psychiatric Hospital, University of Pittsburgh Medical Center, Pittsburgh, Pennsylvania. Dr. Lupu is Adjunct Instructor in Pharmacy and Therapeutics, University of Pittsburgh Western Psychiatric Hospital, University of Pittsburgh Medical Center, Pittsburgh, Pennsylvania. Dr. Gannon is Associate Professor of Psychiatry, Western Psychiatric Hospital, University of Pittsburgh Medical Center, Pittsburgh, Pennsylvania. Ms. Arbutiski is Director of Behavioral Health Services, Western Psychiatric Hospital and Western Behavioral Health, University of Pittsburgh Medical Center, Pittsburgh, Pennsylvania. Dr. Das is Assistant Professor of Medicine, University of Pittsburgh Medical Center, Pittsburgh, Pennsylvania. Dr. Chengappa is Professor of Psychiatry, Western Psychiatric Hospital, University of Pittsburgh Medical Center, Pittsburgh, Pennsylvania.

Disclosures

The authors report no financial relationships with any companies whose products are mentioned in this article, or with manufacturers of competing products.

doi: $10.12788 /$ cp.0204

\section{How would you} handle this case?

Answer the challenge questions at MDedge.com/ psychiatry and see how your colleagues responded 


\section{Clinical Point}

\section{Gastroparesis is diagnosed by a nuclear medicine solid gastric emptying scintigraphy study}

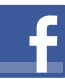

Discuss this article at www.facebook.com/ MDedgePsychiatry
This is not Mr. F's first experience with significant $\mathrm{Gl}$ distress. A few months before his first psychotic episode, Mr. F began developing vision problems, joint and abdominal pain, and a general decline in social and academic functioning. At that time, he underwent a significant workup by both $\mathrm{Gl}$ and integrative medicine, including stool testing, upper endoscopy, and a Cyrex panel (a complementary medicine approach to exploring for specific autoimmune conditions). Results were largely within expected parameters, though a hydrogen breath test was suggestive of possible small intestine bowel overgrowth. More recently, he has been adhering to a gluten-free diet, which his family felt may help prevent some of his physical symptoms as well as mitigate some of his psychotic symptoms. He now asks if he can stop taking clozapine.

\section{What would be the most appropriate next step for Mr. F?}
a) immediately taper the clozapine
b) prescribe ondansetron for nausea
c) introduce diet and lifestyle interventions and try a proton pump inhibitor (PPI)
d) consult GI

\section{EVALUATION Establishing the correct diagnosis}

Initially, Mr. F is diagnosed with gastroesophageal reflux disease (GERD) and attempts to manage his symptoms with pharmacologic and diet-based interventions. He significantly cuts down on soda consumption, and undergoes trials of calcium carbonate, antiemetics, and a PPI. Unfortunately, no material improvements are noted, and he continued to experience significant upper $\mathrm{Gl}$ distress, especially after meals.

The psychiatric treatment team, Mr. F, and his family seek consultation with a Gl specialist, who recommends that Mr. F. undergo a nuclear medicine solid gastric emptying scintigraphy study to evaluate for gastroparesis (delayed gastric emptying). ${ }^{1}$ Results demonstrate grade 3 gastroparesis, with $56 \%$ radiotracer retainment at 4 hours. Mr. F is relieved to finally have an explanation for his persistent $\mathrm{Gl}$ symptoms, and discusses his treatment options with the Gl consultant and psychiatry team.

\section{The authors' observations}

Mr. F and his family are opposed to starting a dopamine antagonist such as metoclopramide or domperidone (the latter is not FDA-approved but is available by special application to the FDA). These are firstline treatments for gastroparesis, but Mr. F and his family do not want them because of the risk of tardive dyskinesia. This is consistent with their previously expressed concerns regarding first-generation antipsychotics, and is why Mr. F has only been treated with a very low dose of haloperidol while the clozapine was titrated. Instead, Mr. F, his family, the psychiatry treatment team, and the GI specialist agree to pursue a combination of a GI hypomotility dietwhich includes frequent small meals (4 to 6 per day), ideally with low fiber, low fat, and increased fluid intake-and a trial of the second line agent for gastroparesis, erythromycin, a medication with known hepatic cytochrome P450 (CYP) drug-drug interactions that impacts the clearance of clozapine.

Shared decision making is an evidencebased approach to engaging patients in medical decision making. It allows clinicians to provide education on potential treatment options and includes a discussion of risks and benefits. It also includes an assessment of the patient's understanding of their condition, explores attitudes towards treatment, and elicits patient values specific to the desired outcome. Even in very ill patients with schizophrenia, shared decision making has been demonstrated to increase patient perception of involvement in their own care and knowledge about their condition. ${ }^{2}$ Using this 
framework, Mr. F and his family, as well as the GI and psychiatric teams, felt confident that the agreed-upon approach was the best one for Mr. F.

\section{TREATMENT Erythromycin and continued clozapine}

Mr. F. is started on erythromycin, $100 \mathrm{mg} 3$ times a day. Erythromycin is a prokinetic agent that acts as a motilin agonist and increases the rate of gastric emptying. The liquid formulation of the medication is a suspension typically taken in 3- to 4-week courses, with 1 week "off" to prevent tachyphylaxis. ${ }^{3}$ Compared to the tablet, the liquid suspension has higher bioavailability, allows for easier dose adjustment, and takes less time to reach peak serum concentrations, which make it the preferred formulation for gastroparesis treatment.

Per the $\mathrm{Gl}$ consultant's recommendation, Mr. F receives a total of 3 courses of erythromycin, with some improvement in the frequency of his nausea noted only during the third erythromycin course. His clozapine levels are closely monitored during this time, as well as symptoms of clozapine toxicity (ie, sedation, confusion, hypersalivation, seizures, myoclonic jerks), because erythromycin can directly affect clozapine levels. ${ }^{4,5}$ Case reports suggest that when these 2 medications are taken concomitantly, erythromycin inhibits the metabolism of hepatic enzyme CYP3A4, causing increased plasma concentrations of clozapine. Before starting erythromycin, Mr. F's clozapine levels were $809 \mathrm{ng} / \mathrm{mL}$ at $350 \mathrm{mg} / \mathrm{d}$. During the erythromycin courses, his levels are 1,043 to 1,074 $\mathrm{ng} / \mathrm{mL}$, despite reducing clozapine to 300 $\mathrm{mg} / \mathrm{d}$. However, he does not experience any adverse effects of clozapine (including seizures), which were being monitored closely.

\section{The authors' observations}

Clozapine is the most effective medication for treatment-refractory schizophrenia. ${ }^{6}$
Compared to the other second-generation antipsychotics, it is associated with a lower risk of rehospitalization and treatment discontinuation, a significant decrease of positive symptom burden, and a reduction in suicidality. ${ }^{78}$ Unfortunately, clozapine use is not without significant risk. FDA black box warnings highlight severe neutropenia, myocarditis, seizures, and hypotension as potentially life-threatening adverse effects that require close monitoring. ${ }^{9}$

Recently, clinicians have increasingly focused on the underrecognized but wellestablished finding that clozapine can cause significant GI adverse effects. While constipation is a known adverse effect of other antipsychotics, a 2016 meta-analysis of 32 studies estimated that the pooled prevalence of clozapine-associated constipation was $31.2 \%$, and showed that patients receiving clozapine were 3 times more likely to be constipated than patients receiving other antipsychotics (odds ratio 3.02, CI 1.91-4.77, $P<.001, \mathrm{n}=11$ studies). ${ }^{10}$ A 2012 review of 16 studies involving potentially lethal adverse effects of clozapine demonstrated that rates of agranulocytosis and GI hypomotility were nearly identical, but that mortality from constipation was 3.6 to 12.5 times higher than mortality from agranulocytosis. ${ }^{11}$

In 2020, the FDA issued an increased warning regarding severe bowel-related complications in patients receiving clozapine, ranging in severity from mild discomfort to ileus, bowel obstruction, toxic megacolon, and death. ${ }^{9}$

As exemplified by Mr. F's case, upper GI symptoms associated with clozapine also are distressing and can have a significant impact on quality of life. Dyspepsia is a common complaint in patients with chronic psychiatric illness. A study of 79 psychiatric inpatients hospitalized longterm found that $80 \%$ reported at least 1 symptom of dyspepsia. ${ }^{12}$ There are few older studies describing the effect of clozapine on the upper GI system. We and

\section{Clinical Point \\ Treatments for gastroparesis include metoclopramine, domperidone, and erythromycin}




\section{Clinical Point}

\section{A review of 16 clozapine studies found that mortality from constipation was higher than mortality from agranulocytosis}

\section{Table}

\section{GERD and gastroparesis: A comparison}

\begin{tabular}{|c|c|c|}
\hline & GERD & Gastroparesis \\
\hline Prevalence & $\begin{array}{l}\text { Common ( } 15 \% \text { to } 30 \%) \text { in general } \\
\text { community population, varies among } \\
\text { countries }\end{array}$ & $\begin{array}{l}\text { Low }(<.1 \%) \text { in general community } \\
\text { population }\end{array}$ \\
\hline Etiology & $\begin{array}{l}\text { - Anatomical (lower esophageal sphincter } \\
\text { relaxation, hiatal hernia) } \\
\text { - Medication-induced } \\
\text { - Diet } \\
\text { - Obesity } \\
\text { - Pregnancy }\end{array}$ & $\begin{array}{l}\text { - Idiopathic } \\
\text { - Diabetes } \\
\text { - Medication-induced } \\
\text { - Surgical }\end{array}$ \\
\hline Symptoms & $\begin{array}{l}\text { Heartburn, regurgitation, chest pain, } \\
\text { stomach pain, chronic cough, laryngitis, } \\
\text { asthma exacerbation }\end{array}$ & $\begin{array}{l}\text { Abdominal pain and bloating, early } \\
\text { satiety, nausea, vomiting, and heartburn. } \\
\text { Symptoms mostly cluster together and are } \\
\text { noted after eating }\end{array}$ \\
\hline Diagnosis & $\begin{array}{l}\text { - Clinical interview and exam } \\
\text { - PPI trial } \\
\text { - H. Pylori breath test and treatment } \\
\text { - Upper Gl endoscopy (if alarm } \\
\text { symptoms) } \\
\text { - Ambulatory esophageal reflux } \\
\text { monitoring }\end{array}$ & $\begin{array}{l}\text { - Clinical interview and examination } \\
\text { - Imaging } \\
\text { - Upper Gl endoscopy } \\
\text { - Gastric emptying test with scintigraphy } \\
\text { - Wireless motility capsule }\end{array}$ \\
\hline Treatment & $\begin{array}{l}\text { Lifestyle modifications: } \\
\text { - Stop eating }>3 \text { hours before bed } \\
\text { - Decrease intake of spicy foods, citrus, } \\
\text { alcohol, caffeine } \\
\text { - Weight loss } \\
\text { - Smoking cessation } \\
\text { - Elevate the head of the bed while } \\
\text { sleeping } \\
\text { Medications: } \\
\text { - Test and treat for H. Pylori } \\
\text { - Acid suppression (PPIs, H2 receptor } \\
\text { antagonists) } \\
\text { Surgical intervention: } \\
\text { - Nissen fundoplication }\end{array}$ & $\begin{array}{l}\text { Lifestyle modifications: } \\
\text { - Eat } 4 \text { to } 6 \text { small meals each day } \\
\text { - Consume meals with low fat and low } \\
\text { fiber } \\
\text { - Increase liquid intake } \\
\text { Medications: } \\
\text { - As-needed antiemetics } \\
\text { - Prokinetics (metoclopramide, } \\
\text { erythromycin) } \\
\text { Surgical intervention: } \\
\text { - Gastric electric stimulation } \\
\text { - Pyloroplasty }\end{array}$ \\
\hline
\end{tabular}

others previously reported on significantly increased use of - not only antacids-but also $\mathrm{H} 2$ blockers and prokinetic agents after initiating clozapine, but sample sizes are small. ${ }^{13-15}$ These older data and newer studies suggest that GERD is a common upper GI disorder diagnosis following clozapine initiation, perhaps reflecting a knowledge gap and infrequent use of the more complex testing required to confirm a diagnosis of GI motility disorders such as gastroparesis.
In a study of 17 patients receiving clozapine, wireless motility capsules were used to measure whole gut motility, including gastric emptying time, small bowel transit time, and colonic transit time. In $82 \%$ of patients, there was demonstrated GI hypomotility in at least 1 region, and $41 \%$ of participants exhibited delayed gastric emptying, with a cut-off time of $>5$ hours required for a gastroparesis diagnosis. ${ }^{16}$ This is significantly higher than the prevalence of gastroparesis observed in 
studies of the general community. ${ }^{17}$ The Table $^{18,19}$ (page 50) summarizes the differences between GERD and gastroparesis.

\section{OUTCOME Some improvement}

Mr. $\mathrm{F}$ experiences limited improvement of some of his nausea symptoms during the third erythromycin cycle and returns to the gastroenterologist for a follow-up appointment. The Gl specialist decides to discontinue erythromycin in view of potential drug-drug interactions and Mr. F's elevated clozapine levels and the associated risks that might entail. Mr. $F$ is again offered the D2 dopamine antagonist metoclopramide, but again refuses due to the risk for tardive dyskinesia. He is asked to continue the $\mathrm{Gl}$ dysmotility diet. Mr. F finds some relief of nausea symptoms from an over-the-counter product for nausea (a nasal inhalant containing essential oils) and is advised to follow up with the Gl specialist in 3 months. Shortly thereafter, he is discharged to live in a less restrictive supportive housing environment, and his follow-up psychiatric care is provided by an assertive community treatment team. Over the next several months, the dosage of clozapine is decreased to $250 \mathrm{mg} / \mathrm{d}$. Mr. F initially experiences worsening psychiatric symptoms, but stabilizes thereafter. He then moves out of state to be closer to his family.

\section{References}

1. Camilleri M, Chedid V, Ford AC, et al. Gastroparesis. Nat Rev Dis Primers. 2018;4(1):41. doi:10.1038/s41572-018-0038-Z

2. Hamann J, Langer B, Winkler V, et al. Shared decision making for in-patients with schizophrenia. Acta Psychiatr Scand. 2006;114(4):265-273. doi: 10.1111/j.1600-0447.2006.00798.x

\section{Related Resources}

- Camilleri M, Chedid V, Ford AC, et al. Gastroparesis. Nat Rev Dis Primers. 2018;4(1):41. doi:10.1038/s41572-018-0038-Z

- Every-Palmer S, Nowitz M, Stanley J, et al. Clozapinetreated patients have marked gastrointestinal hypomotility, the probable basis of life-threatening gastrointestinal complications: a cross sectional study. EBioMedicine. 2016;5:125-134. doi:10.1016/j.ebiom.2016.02.020

Drug Brand Names

Clozapine $\cdot$ Clozaril

Haloperidol $\cdot$ Haldo

Metoclopramide .

Erythromycin • Erythromycin

Ethylsuccinate oral suspension

3. Maganti K, Onyemere K, Jones MP. Oral erythromycin and symptomatic relief of gastroparesis: a systematic review. Am J Gastroenterol. 2003;98(2):259-263. doi:10.1111/j.1572 0241.2003.07167.x

4. Taylor D. Pharmacokinetic interactions involving clozapine. Br J Psychiatry. 1997;171:109-112. doi:10.1192/ bjp.171.2.109

5. Edge SC, Markowitz JS, Devane CL. Clozapine drugdrug interactions: a review of the literature. Human Psychopharmacology: Clinical and Experimental. 1997; 12(1):5-20 .

6. Vanasse A, Blais L, Courteau J, et al. Comparative effectiveness and safety of antipsychotic drugs in schizophrenia treatment: a real-world observational study. Acta Psychiatr Scand. 2016;134(5):374-384. doi:10.1111/ acps. 12621

7. Siskind D, McCartney L, Goldschlager R, et al. Clozapine v. first- and second-generation antipsychotics in treatmentrefractory schizophrenia: systematic review and metaanalysis. Br J Psychiatry. 2016;209(5):385-392. doi:10.1192/ bjp.bp.115.177261

8. Azorin JM, Spiegel R, Remington G, et al. A doubleblind comparative study of clozapine and risperidone in the management of severe chronic schizophrenia. Am J Psychiatry. 2001;158(8):1305-1313. doi:10.1176/appi. ajp.158.8.1305

9. National Alliance on Mental Illness. Clozapine. Accessed June 13, 2021. https://www.nami.org/About-MentalIllness/Treatments/Mental-Health-Medications/Types-ofMedication/Clozapine-(Clozaril-and-FazaClo)

10. Shirazi A, Stubbs B, Gomez L, et al. Prevalence and predictors of clozapine-associated constipation: a systematic review and meta-analysis. Int J Mol Sci. 2016;17(6):863. doi:10.3390/ijms17060863

11. Cohen D, Bogers JP, van Dijk D, et al. Beyond white blood cell monitoring: screening in the initial phase of clozapine therapy. J Clin Psychiatry. 2012;73(10):1307-1312. doi:10.4088/JCP.11r06977

\section{Clinical Point}

GERD is a common upper GI diagnosis in patients receiving clozapine, but GI motility disorders may be underdiagnosed

\section{Bottom Line}

In patients receiving clozapine, frequent nausea along with clustering of heartburn, abdominal pain, bloating, early satiety, and vomiting (especially after meals) may signal gastroparesis rather than gastroesophageal reflux disease. Such patients may require consultation with a gastroenterologist, a scintigraphy-based gastric emptying test, and treatment if gastroparesis is confirmed. 
12. Mookhoek EJ, Meijs VM, Loonen AJ, et al. Dyspepsia in chronic psychiatric patients. Pharmacopsychiatry. 2005;38(3):125-127. doi:10.1055/s-2005-864123

13. John JP, Chengappa KN, Baker RW, et al. Assessment of changes in both weight and frequency of use of medications for the treatment of gastrointestinal symptoms among clozapine-treated patients. Ann Clin Psychiatry. 1995;7(3):119-125. doi: 10.3109/ 10401239509149038

14. Schwartz BJ, Frisolone JA. A case report of clozapineinduced gastric outlet obstruction. Am J Psychiatry. 1993;150(10):1563. doi:10.1176/ajp.150.10.1563a

15. Taylor D, Olofinjana O, Rahimi T. Use of antacid medication in patients receiving clozapine: a comparison with other second-generation antipsychotics. J Clin Psychopharmacol. 2010;30(4):460-461. doi:10.1097/ JCP.0b013e3181e5c0f7
16. Every-Palmer S, Inns SJ, Grant E, et al. Effects of clozapine on the gut: cross-sectional study of delayed gastric emptying and small and large intestinal dysmotility. CNS Drugs. 2019;33(1):81-91. doi:10.1007/s40263018-0587-4

17. Jung HK, Choung RS, Locke GR 3rd, et al. The incidence, prevalence, and outcomes of patients with gastroparesis in Olmsted County, Minnesota, from 1996 to 2006. Gastroenterology. 2009;136(4):1225-1233. doi: 10.1053/j. gastro.2008.12.047

18. Antunes C, Aleem A, Curtis SA. Gastroesophageal reflux disease. StatPearls Publishing. Updated July 7, 2021. Accessed December 8, 2021. https://www.ncbi.nlm.nih. gov/books/NBK441938/

19. Reddivari AKR, Mehta P. Gastroparesis. StatPearls Publishing. Updated June 30, 2021. Accessed December 8 2021. https://www.ncbi.nlm.nih.gov/books/NBK551528/

\section{Clinical Point \\ In a small study of patients receiving clozapine, $41 \%$ had delayed gastric emptying}

\section{MARKETPLACE}

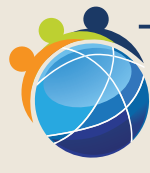

MEDJOBNETWORK, com

Physician $\odot$ NP/PA Career Center

\section{Exciting Opportunity for a Psychiatrist in the Beautiful Southwest}

San Juan Health Partners in Farmington, New Mexico is recruiting a General Psychiatrist. Join a caring, community hospital in the heart of the Four Corners.

You can look forward to:

Compensation range based on years of experience

-Less than two years of experience $\$ 250,000$

-Two or more years of experience $\$ 295,000$

- Productivity/Quality bonus potential

- $1: 4$ call
- Lucrative benefit package, including retirement

- Student loan repayment and residency stipend

- Competitive sign-on and relocation package

- Quality work/life balance

San Juan Regional Medical Center is a non-profit and community governed facility. Farmington offers a temperate four-season climate near the Rocky Mountains with world-class snow skiing, fly fishing, golf, hiking and water sports. Easy access to world renowned Santa Fe Opera, cultural sites, National Parks and monuments. Farmington's strong sense of community and vibrant Southwest culture make it a great place to pursue a work-life balance.

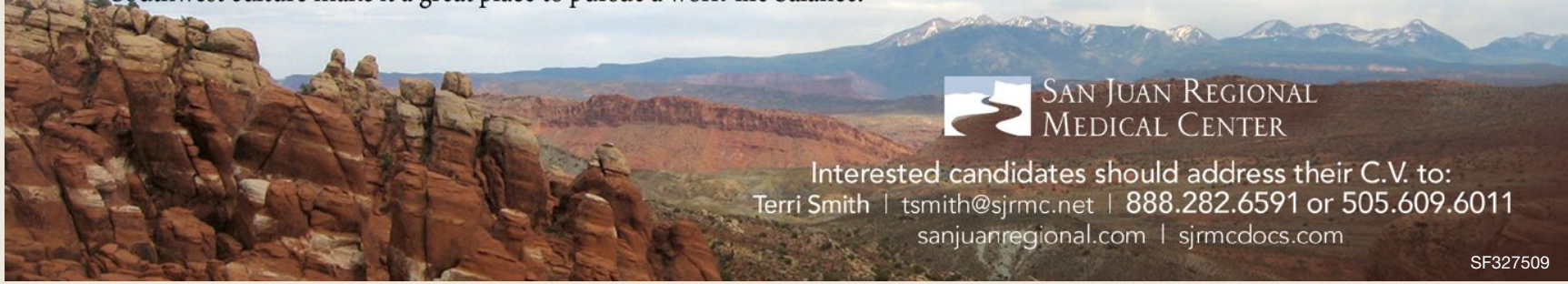

